Singh, B. N., Mathew, S. \& Anand, N. (1958). J. gen. Microbiol, 19, 104-111

\title{
The Role of Aerobacter sp., Escherichia coli and Certain Amino Acids in the Excystment of Schizopyrenus russelli
}

\author{
By B. N. SINGH, S. MATHEW AND NITYA ANAND \\ Central Drug Research Institute, Lucknow, India
}

\begin{abstract}
SUMMARY: Aqueous extracts of Aerobacter sp. and Escherichia coli have been found to cause excystment of viable sterile cysts of Schizopyrenus russelli. The factors which cause excystment are thermostable. With the aid of paper partition chromatography of the aqueous extract of Aerobacter sp., it has been found that part of the excystment-inducing activity is due to the presence of amino acids, some of which have been identified. Amino acids, sugars, purines, pyrimidines, nucleosides, nucleotides and organic phosphates have been tested for their ability to induce excystment. It has been found that some amino acids and a few nucleotides can cause excystment. The effect of $\mathrm{pH}$, concentration and time on excystment with amino acids has been studied.
\end{abstract}

Bacteria and amoebae live in close association in human and animal intestine, and living bacteria in addition to being the usual food for ameobae are believed to be in some way responsible for the excystment of amoeboid cysts. A study of the amoeba excystment factor or factors produced by common intestinal bacteria might be of significance for more effective chemotherapy of chronic amoebic dysentery. Various factors such as hypo- and hypertonicity of the medium, low oxygen tension, change of $\mathrm{pH}$ value, presence of reducing agents or nutrient media, change of temperature, desiccation, presence of bacteria, etc., have been claimed to potentiate the emergence of trophozoites from their resting cysts in Protozoa (see Beers, 1946; Crump, 1950; Hall, 1953; Kudo, 1954; Singh, 1941 $b$ for the earlier literature). Earlier workers in this field, however, do not appear to have fully recognized the risk of contamination by other organisms inherent in such experiments, especially when nutritionally rich media are to be examined for the presence of excystment factors. Unless aseptic conditions are maintained during experiments, the results will remain open to doubt.

It was shown by Singh (1941b) for Colpoda steinii, by Beers (1946) for Didinium nasutum and by Crump (1950) for Amoeba 4(Schizopyrenus russelli, Singh, 1952) that an environment containing bacteria was necessary for the resting cysts of these Protozoa to excyst. Singh, Mathew \& Sreenivasaya (1956) demonstrated that a strain of an Aerobacter sp. produced in an actively proliferating culture an excystment factor for $S$. russelli cysts, which was capable of diffusing easily through a collodion membrane; the factor was thermolabile and its activity was somewhat dependent on the $\mathrm{pH}$ value of the medium.

The present paper deals with the extraction and isolation of material causing excystment from an Aerobacter sp. and from Escherichia coli and examines the role of certain amino acids in excystment. 


\section{METHODS}

\section{Preparation of sterile cysts of Schizopyrenus russelli}

The cysts from a 'pure line' culture of amoebae were used in this work (see Singh, 1952, for the characters of Schizopyrenus russelli and the culture methods used). The cysts are double-walled and excystment takes place in two stages (Crump, 1950). The amoebae were grown on non-nutrient $\operatorname{agar}(2.5 \%, \mathrm{w} / \mathrm{v}$, agar), $0.5 \%(\mathrm{w} / \mathrm{v}) \mathrm{NaCl} ; \mathrm{pH} 6 \cdot 8-7 \cdot 0$; plates supplied with a young culture (3 days old) of Aerobacter sp. grown on nutrient agar slopes (Strain 1912; Singh, 1941 $a$ ). Ten-day-old cysts were collected and washed three times by suspension and centrifugation in sterile distilled water at $500 \mathrm{rev} . / \mathrm{min}$. for $3 \mathrm{~min}$., in order to get rid of most of the bacteria. They were then treated with a mixture of penicillin (200 units $/ \mathrm{ml}$.) and streptomycin (1000 units/ml.) for $48 \mathrm{hr}$. at $25^{\circ}$ to kill bacteria, centrifuged, and washed with distilled water. The cysts were next treated with $0.5 \%(w / v)$ emetine hydrochloride or $\mathrm{HCl}$ $(1 \cdot 0-1.5 \%, w / v)$ for $24 \mathrm{hr}$. to destroy active amoebae or partially formed cysts. After washing, these sterile cysts were kept in $0.85 \%(\mathrm{w} / \mathrm{v}) \mathrm{NaCl}$ solution at $4^{\circ}$ and were used for excystment experiments during 4 weeks, when there was hardly any loss in viability. The freedom of these cysts from bacteria was tested on nutrient agar slopes or in nutrient broth, and their viability by inoculating them in the presence of living Aerobacter sp. on non-nutrient agar. The sterile cysts excysted readily in the presence of living bacteria on the non-nutrient agar, although on non-nutrient agar alone there was hardly any excystment.

\section{Method of studying excystment}

Petri dishes, each containing a flat-bottom cavity slide placed on a piece of filter paper, were sterilized $\left(160^{\circ}\right.$ for $1 \mathrm{hr}$.). A very tiny drop (c. $0.001 \mathrm{ml}$.) of cyst suspension, containing 50-125 cysts, was transferred to the centre of the cavity slide by a finely drawn capillary pipette. A small drop of the test fluid (c. 0.005-0.01 ml.) was then added and the filter paper was moistened with sterile distilled water to prevent evaporation of the liquid in the cavity slide. These Petri dishes were then incubated at $24-25^{\circ}$ for 18-24 hr. After this period, the cavity of the slide was sealed with a sterile coverslip, the slide inverted carefully and examined under the low power of a microscope. The fluid containing the cysts remained as a drop and did not spread out. A cyst was considered excysted only when an amoeba escaped from it and was found to be moving freely in the surrounding medium. The percentage excystment was calculated from the count of the amoebae and the unexcysted cysts. As there was no food supply for the excysted amoebae, they remained viable for 72$96 \mathrm{hr}$. and then died or tried to encyst. To ascertain whether sterile conditions had prevailed during the experiment, the fluid from the cavity slides was drawn out at the end of the experiment and was inoculated into nutrient broth or on nutrient agar. 


\section{Preparation of the aqueous extracts of bacteria}

(1) Aerobacter sp., Escherichia coli and E. coli strain RCI (phage-resistant strain of E. coli; Gupta, 1957) were grown in a liquid defined medium $\left(\mathrm{NH}_{4} \mathrm{Cl}\right.$, 1 g.; $\mathrm{MgSO}_{4}$. $7 \mathrm{H}_{2} \mathrm{O}, 0.1 \mathrm{~g}$.; $\mathrm{KH}_{2} \mathrm{PO}_{4}, 1.5 \mathrm{~g}$.; $\mathrm{Na}_{2} \mathrm{HPO}_{4}, 3.5 \mathrm{~g}$.; lactic acid, 9.0 g.; distilled water, $1000 \mathrm{ml}$.; $\mathrm{pH} \mathrm{6.8-7.0)}$ at $37^{\circ}$ for $17 \mathrm{hr}$. The organisms were washed thrice with distilled water by centrifugation. They were then killed by suspending them in ice-cold acetone for $30 \mathrm{~min}$., washed once with acetone and dried in a vacuum desiccator. The dried organisms were ground with sterile glass dust and distilled water in a mortar, and the water-soluble portion collected by centrifugation. This aqueous extract was sterilized at $15 \mathrm{lb}$./sq.in. pressure for $15 \mathrm{~min}$. and had a $\mathrm{pH}$ value of about $6 \cdot 8-7 \cdot 0$. The bacterial residue was washed three times and suspended in distilled water.

(2) The washed Aerobacter sp. (17 hr. old) was suspended in distilled water, heated at $100^{\circ}$ for $20 \mathrm{~min}$. in a water bath (Freeland \& Gale, 1947) and centrifuged. The supernatant liquid was at $\mathrm{pH} 6 \cdot 5$. The organisms were washed three times and suspended in distilled water.

\section{RESULTS}

Effect of aqueous extracts of bacteria on excystment

The excystment properties of the aqueous extract and of the bacterial residue suspension of the Aerobacter sp., Escherichia coli, E. coli strain RCI, distilled water and normal saline were tested in duplicate; the results are given in

Table 1. The effect of various preparations on excystment

\begin{tabular}{|c|c|c|c|c|c|}
\hline & \multicolumn{5}{|c|}{ Duration of storage at $4^{\circ}$ (days) } \\
\hline & 1 & $\mathbf{3}$ & 5 & 7 & 14 \\
\hline & \multicolumn{5}{|c|}{ Degree of excystment $(\%)^{*}$} \\
\hline \multicolumn{6}{|l|}{ Extract of: } \\
\hline Aerobacter sp. & 96 & 92 & 95 & 85 & 87 \\
\hline Escherichia coli & 93 & 90 & - & 83 & 76 \\
\hline E. coli strain RCI & 96 & - & 98 & - & - \\
\hline $\begin{array}{l}\text { Bacterial residue suspended in distilled } \\
\text { water }\end{array}$ & Nil & Nil & Nil & Nil & Nil \\
\hline Distilled water (control) & Nil & 1.5 & Nil & Nil & Nil \\
\hline Normal saline & Nil & Nil & $2 \cdot 6$ & Nil & Nil \\
\hline
\end{tabular}

Table 1. The variation in the \% excystment of duplicate sets was very little. The fact that the aqueous extract showed marked ability to induce excystment while the bacterial residue suspension was unable to do so, indicated that the bacterial products which induce excystment are water soluble. Storage of the extracts up to a period of 14 days at $4^{\circ}$ or autoclaving at $15 \mathrm{lb}$./sq.in. for $20 \mathrm{~min}$. had practically no adverse effect on excystment.

It is known (Singh, 1946) that cysts produced on different occasions under 
similar cultural conditions may vary in their \% viability. Therefore, it is important to know the \% viability of a batch of cysts before using them in excystment experiments. The ability of the extracts of Aerobacter sp. and of Escherichia coli to cause a high \% excystment provided a useful method of finding out the $\%$ viability in a particular batch of cysts.

\section{Effect of $\mathrm{pH}$ value of a bacterial extract on excystment}

The extract of acetone-killed Aerobacter sp. (pH. 6.8) was adjusted to different $\mathrm{pH}$ values between 2 and 8 by adding $\mathrm{HCl}$ or $\mathrm{NaOH}$. There was no excystment at $\mathrm{pH} \mathrm{2-3;} \mathrm{pH} \mathrm{6-8}$ was found to be most favourable range for the excystment of Schizopyrenus russelli.

\section{Characterization of excystment-causing factors from the water-soluble extract of Aerobacter sp.}

The water-soluble extract (W) of Aerobacter sp. which showed $93 \%$ excystment, obtained from organisms killed by acetone, was evaporated to dryness below $50^{\circ}$, under reduced pressure. It was extracted with $80 \%(\mathrm{v} / \mathrm{v})$ ethanol in water and centrifuged. The insoluble residue $(R)$ when dried and dissolved in distilled water, showed a greatly decreased ability to cause excystment. The ethanolic solution (E) was evaporated to dryness and the residue dissolved in distilled water; it was very effective in causing excystment. This solution showed a strong positive ninhydrin reaction, a positive test for sugars (aniline hydrogen phthalate) and a positive test for organic phosphate. This material was fractionated by paper partition chromatography. The solution was applied to a sheet of Whatman No. 1 filter paper as a streak and the paper developed with butanol +acetic acid + water $(4: 1: 5)$ as the solvent system by the descending technique. The solvent was allowed to travel to the edge of the paper, the paper dried and a narrow segment of the chromatogram cut from one side and sprayed with ninhydrin for the location of the amino acids. Nine distinct ninhydrin-positive spots were visible. The chromatogram was then divided into twenty bands, ten corresponding to the ninhydrin-positive bands and ten other bands. These bands were excised, eluted with water and the eluates autoclaved and tested for their excystment properties. Six of these fractions showed excystment activity; five of these corresponded with the five slower-moving ninhydrin-positive bands. The sixth fraction $\left(\boldsymbol{R}_{\boldsymbol{r}} \mathbf{0 . 5 3 -}\right.$ 0.63) with a ninhydrin-negative zone; this fraction has not yet been identified.

Paper chromatography of the aqueous extract $(W)$ was repeated with the same solvent system. To obtain better resolution of the amino acids, the chromatogram was allowed to run $30 \mathrm{hr}$. and a segment of the paper developed with ninhydrin as before. Again nine strong and two weak ninhydrin-positive spots were obtained. The bands corresponding to the nine distinct ninhydrinpositive spots were marked on the chromatogram, the bands excised, eluted with water and the eluates tested for the excystment activity. Table 2 gives a summary of the results, the $\boldsymbol{R}_{\boldsymbol{i}}$ value of the fractions and the corresponding $\%$ excystment obtained. It is clear from Table 2 that only the six slowmoving fractions showed excystment activity; of these, fractions one and five 
were most active. The inability of the other fractions to cause excystment may have been due to a low concentration of these amino acids. The amino acids identified in these fractions by two-dimensional chromatography were cystine, lysine, arginine, histidine, aspartic acid or glycine, glutamic acid, alanine, tyrosine, valine, isoleucine or phenylalanine (Table 2). The solvent systems used were butanol + acetic acid + water $(4: 1: 5)$ and phenol + water + ammonia (80:20 with $3 \%$ ammonia). Further work to characterize the excystment-causing material insoluble in $80 \%(\mathrm{v} / \mathrm{v})$ ethanol in water and the determination of the relative concentration of amino acids is in progress.

Table 2. Excystment caused by amino acids isolated from the water-soluble extract of Aerobacter sp. by paper chromatography

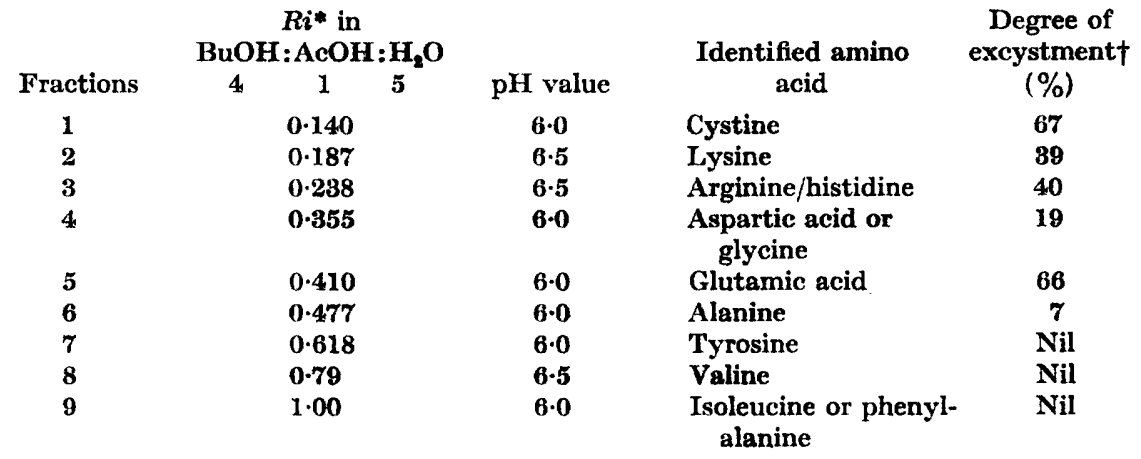

* $\boldsymbol{R}_{i}$ refers to the distance travelled by individual fractions from the origin as compared to that of isoleucine taken as 1 .

$\dagger$ Mean of duplicate sets.

The finding that the bacterial products of the Aerobacter sp. which caused excystment were water soluble and that part of this activity was due to amino acids, led to the testing of various pure amino acids for their excystment inducing activity. Certain sugars, purines, pyrimidines, nucleosides, nucleotides, and vitamins $B_{1}, B_{2}, B_{6}$ were also examined.

Effects of various amino acids on excystment. The excystment inducing activity of twenty-three amino acids dissolved in distilled water and autoclaved was tested (Table 3 ). Some of them induced good excystment, while others induced poor or no excystment. Since the low $\mathrm{pH}$ value of the aqueous extract of Aerobacter sp. was a limiting factor and $\mathrm{pH}$ values between 6 and 8 were most favourable for excystment, some of the amino acids were tested at different $\mathrm{pH}$ values. Solutions of DL-histidine dihydrochloride, DL-lysine dihydrochloride, L-cysteic acid, L-histidine and glutathione, which gave no excystment at $\mathrm{pH}$ 1.0-3.0 gave good excystment at $\mathrm{pH} 7$. There were, however, some amino acids which caused poor or no excystment even in the favourable $\mathrm{pH}$ range of 5.0-7.0 (Table 3 ).

To study the effect of the concentration of amino acids on excystment,

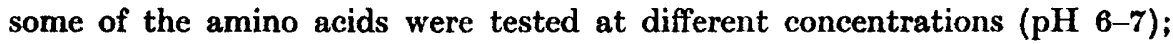
the results are recorded in Table 4. It was found that a definite concentration 
was necessary to give good excystment. There was a certain degree of variation in $\%$ excystment when cysts from different batches were tested with the same amino acids. Therefore, to get comparative \% excystment, different substances should be tested with the same batch of cysts.

Table 3. The effect of various amino acids on excystment

\begin{tabular}{|c|c|c|c|}
\hline Amino acid & Concentration & pH & $\begin{array}{c}\text { Degree of } \\
\text { excystment* } \\
(\%)\end{array}$ \\
\hline DL-Valine & & $6 \cdot 0$ & 68 \\
\hline DL-Serine & & $6 \cdot 8$ & 69 \\
\hline DL-Methionine & & $6 \cdot 0$ & 52 \\
\hline Glycine & & 6.0 & 45 \\
\hline DL-Histidine dihydrochloride & & $1 \cdot 0$ & Nil \\
\hline DL-Threonine & & $5 \cdot 0$ & 49 \\
\hline DL-Proline & & $7 \cdot 0$ & $\mathbf{4 7}$ \\
\hline DL-Isoleucine & $2 \cdot 0 \%(w / v)$ & $6 \cdot 5$ & $\mathbf{5 3}$ \\
\hline DL-Lysine dihydrochloride & & $1 \cdot 0$ & Nil \\
\hline DL- $\beta$-Phenylalanine & & $6 \cdot 0$ & 27 \\
\hline L-Asparagine & & $5 \cdot 0$ & Nil \\
\hline L-Glutamic acid & & $6 \cdot 0$ & 61 \\
\hline DL-Aspartic acid & & $3 \cdot 0$ & Nil \\
\hline DL-Leucine & & 6.5 & 7 \\
\hline DL- $\alpha$-Alanine & & 6.0 & 15 \\
\hline L-Hydroxyproline & & $(7 \cdot 2$ & 76 \\
\hline L-Cysteic acid & & 1.0 & Nil \\
\hline L-Histidine & & 1.0 & Nil \\
\hline L-Arginine & $5.0 \%(w / v)$ & $7 \cdot 0$ & 25 \\
\hline $\mathrm{DL}-$ Ornithine $\mathrm{HCl}$ & & 0.0 & 2 \\
\hline Glutathione & & $3 \cdot 0$ & Nil \\
\hline DL-Alanyl-D-asparagine & & 8.0 & 9 \\
\hline Sarcosine & & $5 \cdot 0$ & Nil \\
\hline
\end{tabular}

* Mean of duplicate sets.

Table 4. The effect of the concentration of amino acids on excystment

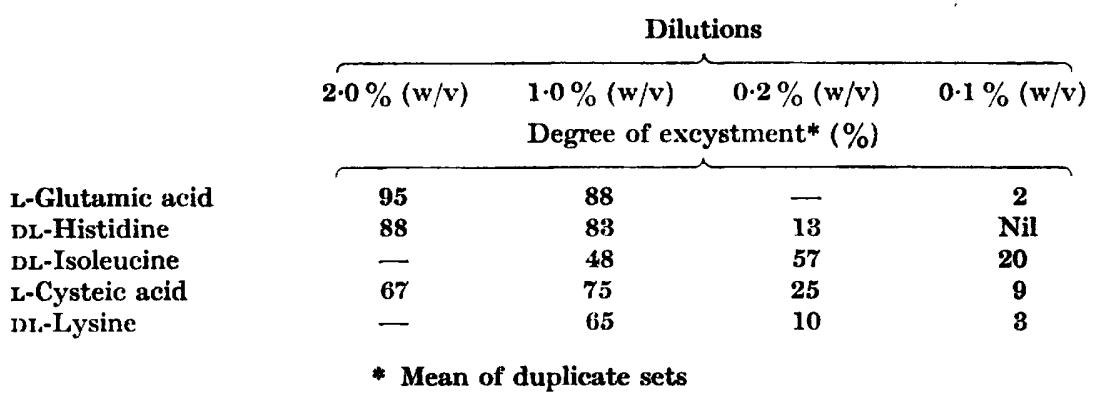

Effect of sugars on excystment. 1.0 and $0.5 \%(\mathrm{w} / \mathrm{v})$ aqueous solutions of arabinose, maltose, raffinose, glucose, lactose, ribose and glucosamine were sterilized by autoclaving ( $15 \mathrm{lb}$./sq.in. for $20 \mathrm{~min}$.) and tested for their excystment properties. There was no excystment in the presence of these compounds. 
Effect of purines, pyrimidines, nucleosides, nucleotides and some organic phosphates on excystment. As certain purines, pyrimidines, nucleosides and nucleotides or organic phosphates might be present in the free state in the metabolic pool in the bacteria, $1.0 \%(\mathrm{w} / \mathrm{v})$ solutions of uracil, uridine, cytidine, adenosine, uridylic acid, guanylic acid, yeast and muscle adenylic acids, and $0.5 \%(\mathrm{w} / \mathrm{v})$ solutions of adenosine triphosphate, $\beta$-glycerophosphate, fructose-6-phosphate, glucose-1-phosphate, potassium metaphosphate and $0.2 \%(\mathrm{w} / \mathrm{v})$ solutions of cytosine, hypoxanthine and adenine were tested for their ability to induce excystment. Only muscle adenylic acid, adenosine triphosphate and fructose-6-phosphate induced excystment of 35, 65 and $42 \%$ respectively; the other compounds were ineffective. Muscle adenylic acid was tested at $2 \cdot 0, \mathbf{1} \cdot 0,0 \cdot 2$ and $0 \cdot 1 \%(\mathrm{w} / \mathrm{v})$ concentrations and the percentage excystment of these was $42,35,9$ and $3 \%$, respectively, showing that higher concentrations caused better excystment.

Effect of vitamins on excystment. Samples of vitamins $\mathbf{B}_{1}, \mathbf{B}_{2}$ and $\mathbf{B}_{6}$ were dissolved in distilled water, autoclaved and tested for excystment properties. Only vitamin $B_{1}$ at a dilution of $1.0 \%(w / v)$ induced excystment.

Excystment of Schizopyrenus russelli cysts at different intervals in the presence of excystment inducing agents. $1.0 \%(\mathrm{w} / \mathrm{v})$ solution of L-glutamic acid, L-cysteic acid and aqueous extract of acetone-killed Aerobacter sp. at $\mathrm{pH} \mathbf{7 \cdot 0}$ were used in this experiment, keeping distilled water as control. In the presence of the bacterial extract the excystment was somewhat more rapid in the first few hours, and at the end of $24 \mathrm{hr}$. all the viable cysts had excysted. The excysted amoebae remained viable in amino acids during $96 \mathrm{hr}$. without multiplying or encysting.

The authors' thanks are due to Dr B. Mukerji, Director, Dr M. L. Dhar, Assistant Director (Medicinal Chemistry) for their interest in this work, Dr B. M. Gupta for the phage-resistant strain of Escherichia coli, strain RCI and Mr K. L. Gulati for technical assistance.

\section{REFERENCES}

BeErs, C. D. (1946). Excystment in Didinium nasutum, with special reference to the role of bacteria. J. exp. Zool. 103, 201.

Crump, L. M. (1950). The influence of bacterial environment on.the excystment of amoebae from soil. J. gen. Microbiol. 4, 16.

Freeland, J. C. \& Gale, E. F. (1947). Amino acid composition of certain bacteria and yeasts. Biochem. J. 41, 135.

GuPTA, B. M. (1957). Antibiotic sensitivity and biochemical reactions of virusresistant and susceptible strains of Escherichia coli. Proc. 44th Indian Sci. Congr. Ass. 19.

Hall, R. P. (1953). Protozoology. New York: Prentice-Hall, Inc.

Kudo, R. R. (1954). Protozoology, 4th ed., Springfield, Illinois, U.S.A.: Charles C. Thomas.

Singh, B. N. (1941 $a)$. Selectivity in bacterial food by soil amoebae in pure mixed culture and in sterilized soil. Ann. appl. Biol. $28,52$.

Singh, B. N. (1941b). The influence of different bacterial food supplies on the rate of reproduction in Colpoda steinii, and the factors influencing encystment. Ann. appl. Biol. 28, 65. 
Singr, B. N. (1946). A method of estimating the numbers of soil Protozoa, especially amoebae, based on their differential feeding on bacteria. Ann. appl. Biol. 33, 112.

SingH, B. N. (1952). Nuclear division in nine species of small free living amoebae and its bearing on the classification of the order Amoebida. Phil. Trans. B, 236, 405.

Singh, B. N., Mathew, S. \& Sreenivasaya, M. (1956). Occurrence and nature of amoeba excystment factor produced by Aerobacter sp. Nature, Lond. 177, 621.

(Received 28 January 1958) 